\title{
User Acceptance Testing (UAT) Refreshment PBX Outlet Site BNI Kanwil Padang
}

\author{
Eko Suprapto \\ Jurusan Teknik Listrik, Fakultas Teknik, Universitas Batanghari \\ Corresponding author, e-mail: eko.suprapto@unbari.ac.id
}

\begin{abstract}
Abstrak. Kualitas suatu sistem aplikasi yang dibuat dapat diketahui dengan melakukan pengujian terhadap sistem tersebut dengan suatu nilai yang terukur. Salah satu metode yang dapat digunakan untuk mengukur penerimaan dan penggunaan teknologi adalah metode uji penerimaan pengguna atau user acceptance test (UAT). Penelitian ini bertujuan untuk menentukan tingkat keberterimaan upgrade PABX menjadi IP PBX di BNI Kanwil Padang. Upgrade sistem dengan menambahkan server VoIP dan perangkat IP Phone dan memanfaatkan jaringan LAN yang sudah tersedia, tanpa merobah topologi jaringan LAN existing. Perobahan ini bertujuan untuk memaksimalkan fungsi layanan komunikasi suara tanpa mengganggu komunikasi data yang sudah ada, sehingga fitur data dan suara bisa dimanfaatkan secara bersamaan dan memaksimalkan jaringan yang sudah tersedia. Jenis UAT yang digunakan dalam penelitian ini adalah Black Box Testing. Uji fungsional ini digunakan untuk menguji perangkat lunak tanpa mengetahui struktur internal kode atau program. Penggunaan jaringan IP memungkinkan penekanan biaya dikarenakan tidak perlu membangun sebuah infrastruktur baru untuk komunikasi suara dan penggunaan lebar data (bandwidth) yang lebih kecil dibandingkan telepon biasa.
\end{abstract}

Kata Kunci : VoIP, PBX, PABX, UAT.

\section{PENDAHULUAN}

Teknologi dalam telekomunikasi dianggap sebagai segala sesuatu yang berkaitan dengan penggunaan alat bantu untuk memproses dan mentransfer informasi. Perkembangan teknologi yang semakin pesat nan kompetitif menuntut para pengembang IT untuk terus meningkatkan berbagai macam inovasi dalam berbagai aspek. Dengan adanya inovasi dari teknologi telekomunikasi diharapkan memberikan efisiensi waktu, biaya dan tenaga serta pikiran. Bahkan didalam komunikasi pemanfaat teknologi dapat dengan mudah terimplementasikan. Faktor geografis dan demografis tidak menjadi halangan bagi orang untuk melakukan komunikasi. Telepon merupakan kebutuhan telekomunikasi yang paling utama. Hal ini dikarenakan pada lingkunan perkantoran dan perusahaan, telepon hampir bisa disamakan dengan kebutuhan pokok manusia. Beberapa provider internet di Indonesia telah membangun infrastruktur untuk menunjang hal tersebut, tetapi biaya yang ditawarkan menjadi sangat mahal. Banyak solusi yang dapat dilakukan untuk mengatasi mahalnya biaya komunikasi yang dilakukan, salah satunya dengan memanfaatkan jaringan IP (Internet Protocol) untuk melewatkan trafik suara atau yang lebih dikenal dengan istilah

VoIP (Voice over Internet Protocol). VoIP dapat dihandalkan untuk saling bertukar informasi dan data, bahkan dapat saling berkomunikasi dan bertukar informasi berupa trafik suara, gambar atau video. Penggunaan teknologi VoIP yang lebih efisien akan semakin dipermudah karena dapat digabungkan dengan jaringan telepon PSTN (Public Switched Telephone Network) lokal yang ada, dengan menggunakan VoIP gateway yang akan disambungkan dengan PABX (Private Automatic Branch eXchange). Prinsip kerja VoIP inilah yang akan mengubah suara menjadi kode digital melalui jaringan paket-paket data, bukan sirkuit analog telepon biasa. Penggunaan jaringan IP memungkinkan penekanan biaya dikarenakan tidak perlu membangun sebuah infrastruktur baru untuk komunikasi suara dan penggunaan lebar data (bandwidth) yang lebih kecil dibandingkan telepon biasa.

Teknologi Multiprotocol Label Switching (MPLS). MPLS merupakan suatu teknik untuk mengintegrasikan teknologi Internet Protocol (IP) dengan Asynchronous Transfer Mode (ATM) dalam jaringan backbone yang sama.

Jaringan baru ini memiliki beberapa hal penting diantaranya :

a. MPLS mengurangi banyaknya proses pengolahan yang terjadi di IP routers, serta memperbaiki kinerja pengiriman suatu paket data.

b. MPLS juga bisa menyediakan Quality of Service (QoS) dalam jaringan backbone, dan menghitung parameter QoS menggunakan teknik Differentiated services (Diffserv) sehingga setiap layanan paket yang dikirimkan akan mendapat perlakuan yang berbeda sesuai dengan skala prioritasnya.

Dengan kebihan ini maka MPLS merupakan terobosan baru dalam hal penanganan paket data. VoIP secara umum didefinisikan sebagai suatu teknologi yang memungkinkan komunikasi suara menggunakan jaringan berbasis IP (Internet Protocol). Untuk penelitian ini VoIP akan dilewatkan pada jaringan MPLS berbasis IPv6. Konsep jaringan MPLS menggunakan switching node yang biasa disebut Label Switching Router (LRS) dengan melekatkan suatu label dalam setiap paket data yang datang, dan menggunakan label tersebut untuk menentukan ke arah mana seharusnya 
paket data tersebut dikirimkan. Jaringan ini terdiri dari titik-titik LSR dan bukan merupakan jaringan IP ataupun jaringan ATM, tetapi merupakan jaringan baru dan berbeda.

Dalam penelitian ini dititikberatkan pada jaringan VoIP over MPLS berbasis IPv6, dimana dalam pengujian akan dibandingkan dengan menggunakan sebuah simulasi. Selain itu juga mengukur QoS jaringan VoIP yang mengimplementasikan sistem IPv6.

Multiprotocol Label Switching (MPLS) merupakan sebuah teknik yang menggabungkan kemampuan manajemen switching yang ada dalam teknologi ATM dengan fleksibilitas network layer yang dimiliki teknologi IP. Fungsi label pada MPLS adalah sebagai proses penyambungan dan pencarian jalur dalam jaringan komputer. MPLS menggabungkan teknologi switching di layer 2 dan teknologi routing di layer 3 sehingga menjadi solusi jaringan terbaik dalam menyelesaikan masalah kecepatan, scalability, QOS (Quality of Service), dan rekayasa trafik. Dengan informasi label switching yang didapat dari routing network layer, setiap paket hanya dianalisa sekali di dalam router di mana paket tersebut masuk ke dalam jaringan untuk pertama kali. Router tersebut berada di tepi dan dalam jaringan MPLS yang biasa disebut dengan Label Switching Router (LSR).

Ide dasar teknik MPLS ini ialah mengurangi teknik pencarian rute dalam setiap router yang dilewati setiap paket, sehingga sebuah jaringan dapat dioperasikan dengan efisien dan jalannya pengiriman paket menjadi lebih cepat. Jadi MPLS akan menghasilkan high-speed routing dari data yang melewati suatu jaringan yang berbasis parameter quality of service (QoS). Berikut ini perbandingan dari label switching dan routing pada IP konvensional.

VoIP secara umum didefinisikan sebagai suatu teknologi yang memungkinkan komunikasi suara menggunakan jaringan berbasis IP (Internet Protocol). Informasi suara yang berupa sinyal analog tersebut dirubah ke dalam bentuk sinyal digital kemudian oleh sistem codec dirubah formatnya menjadi paket - paket data yang selanjutnya akan ditransmisikan ke tujuan melalui jaringan IP atau packet network. VoIP over MPLS adalah suatu system yang menggunakan jaringan perantara dengan arsitektur jaringan MPLS untuk mengirimkan data paket VoIP dari suatu tempat ke tempat yang lain. Alasan pemilihan jaringan berbasis MPLS sebagai testbed jaringan dalam tugas akhir ini karena MPLS menyatukan antara performansi dan kemampuan manajemen trafik dari lapisan Data Link, sehingga dapat diukur dan mempunyai fleksibilitas yang tinggi untuk fungsi routing.

Quality of Service (QoS), sebagaimana dijelaskan dalam rekomendasi CCITT E.800 adalah : "Efek kolektif dari kinerja layanan yang menentukan derajat kepuasan seorang pengguna terhadap suatu layanan" Jika dilihat dari ketersediaan suatu jaringan, terdapat karakteristik kuantitatif yang dapat dikontrol untuk menyediakan suatu layanan dengan kualitas tertentu. Kinerja jaringan VoIP - softswitch dievaluasi berdasarkan parameter - parameter kualitas layanan VoIP, yaitu delay, jitter, packetloss dan throughput. Berikut ini adalah definisi singkat dari keempat parameter layanan VoIP tersebut.

1. Jitter

Merupakan variasi delay yang terjadi akibat adanya selisih waktu atau interval antar kedatangan paket di penerima.

2. Delay

a. Waktu yang dibutuhkan untuk mengirimkan data dari sumber (pengirim) ke tujuan (penerima).

b. Delay maksimum yang direkomendasikan oleh ITU untuk aplikasi suara adalah $150 \mathrm{~ms}$, dan yang masih bisa diterima pengguna adalah $250 \mathrm{~ms}$

3. Paket Loss

Kehilangan paket ketika terjadi peak load dan congestion (kemacetan transmisi paket akibat padatnya traffic yang harus dilayani) dalam batas waktu tertentu.

4. Throughput

Aspek utama throughput yaitu berkisar pada ketersediaan bandwidth yang cukup untuk suatu aplikasi. Hal ini menentukan besarnya trafik yang dapat diperoleh aplikasi saat melewati jaringan.

\section{Panduan Dokumen User Acceptance Test (Uat)}

1. User Acceptance Testing (UAT) merupakan proses verifikasi bahwa solusi yang dibuat dalam sistem sudah sesuai untuk pengguna. Proses ini berbeda dengan pengujian sistem (memastikan software tidak crash dan sesuai dengan dokumen permintaan pengguna), melainkan memastikan bahwa solusi dalam sistem tersebut akan bekerja untuk pengguna (yaitu, tes bahwa pengguna menerima solusi di dalam sistem).

2. UAT umumnya dilakukan oleh klien atau pengguna akhir, biasanya tidak fokus pada identifikasi masalah sederhana seperti kesalahan ejaan, maupun di cacat showstopper, seperti crash perangkat lunak. Penguji dan pengembang mengidentifikasi dan memperbaiki masalah ini selama tahap awal pengujian fungsionalitas, pengujian saat integrasi dan pada tahap sistem testing.

3. Jenis UAT terdiri dari :
a. Alpha \& Beta Testing
b. Contract Acceptance Testing
c. Regulation Acceptance Testing
d. Operational Acceptance Testing 


\section{e. Black Box Testing}

\section{METODE}

Pada penelitian ini menggunakan beberapa metode studi pustaka dan User Acceptance Testing (UAT) yang merupakan proses verifikasi bahwa solusi yang dibuat dalam sistem sudah sesuai untuk pengguna.

\section{HASIL DAN PEMBAHASAN}

Jenis UAT yang digunakan dalam penelitian ini adalah Black Box Testing. UAT Jenis Black Box Testing sering dikategorikan sebagai pengujian fungsional, sampai batas tertentu, dilihat sebagai jenis User Acceptance Test. Pada dasarnya, metode pengujian ini menganalisis fungsi tertentu tanpa membiarkan tester melihat struktur kode internal perangkat lunak. Oleh karena itu, Black Box Testing juga dapat diterapkan untuk UAT, karena Black Box Testing memiliki prinsip yang sama seperti UAT. Selama Black Box Testing, pengguna tidak mengetahui adanya basis kode, tapi hanya tentang persyaratan yang perangkat lunak harus memenuhi.

Hasil UAT ditampilkan dalam tabel berikut ini :

Tabel 1. Hasil UAT

\begin{tabular}{|c|l|l|l|}
\hline No & \multicolumn{1}{|c|}{ Deskripsi } & \multicolumn{1}{c|}{ Status } & \multicolumn{1}{c|}{ Keterangan } \\
\hline 1 & Dokument UAT check list & UAT Sukses & Dokumen Terlampir \\
\hline 2 & Dokumentasi perangkat Server & UAT Sukses & Dokumen Terlampir \\
\hline 3 & Dokumentasi telephone & UAT Sukses & Dokumen Terlampir \\
\hline
\end{tabular}

Tahapan pengujian :

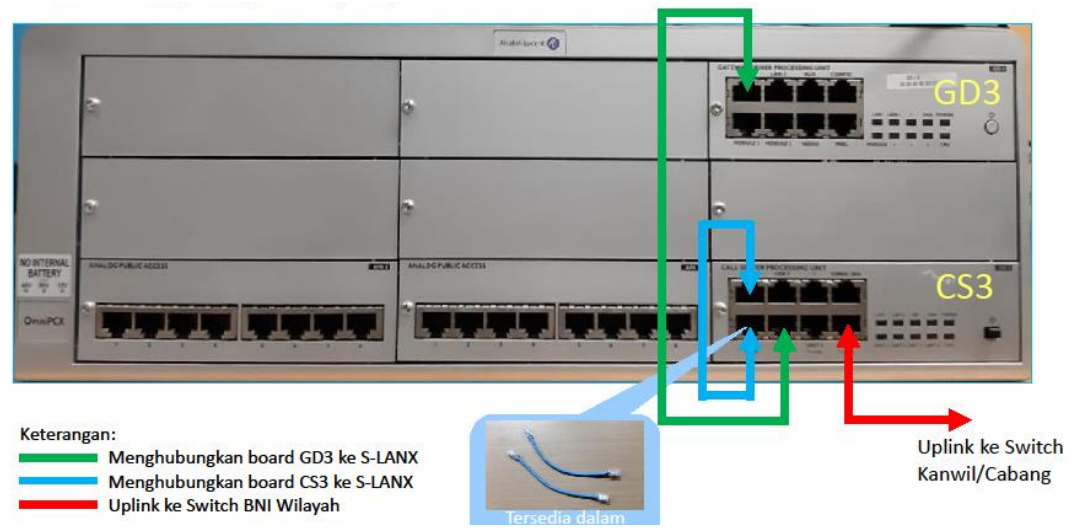

Gambar 1. PABX Shelf

Gambar Server Recording

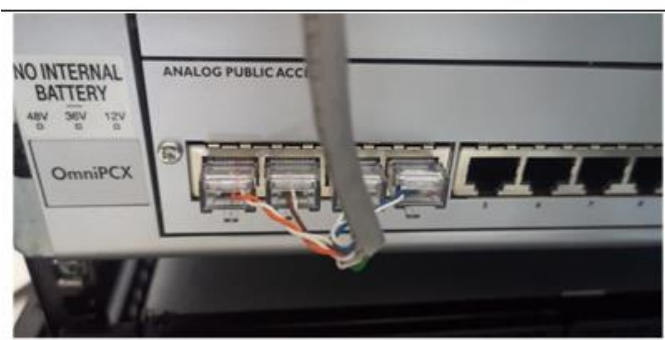

Gambar ESR

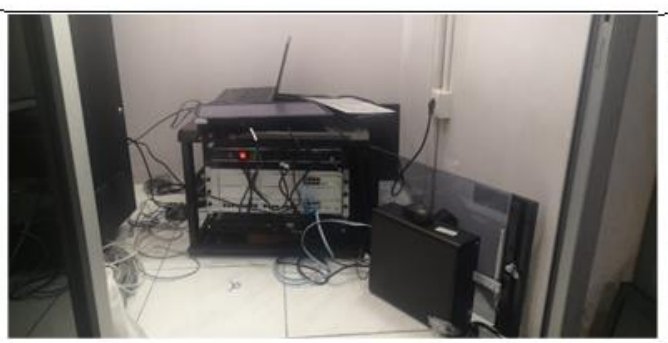

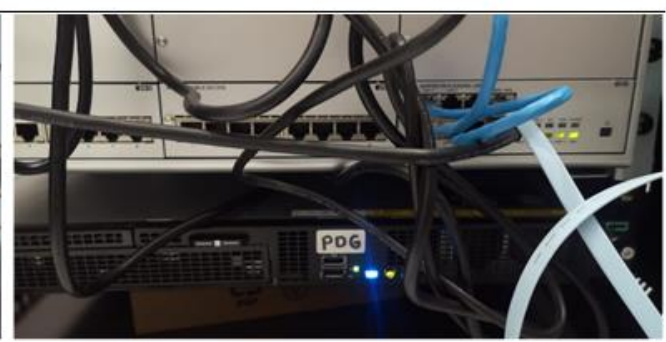

Gambar Keseluruhan

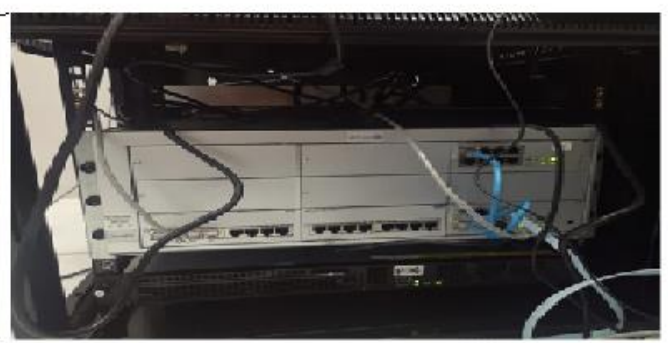

Gambar 2. Server 
Gambar Telephone di Resepsionis
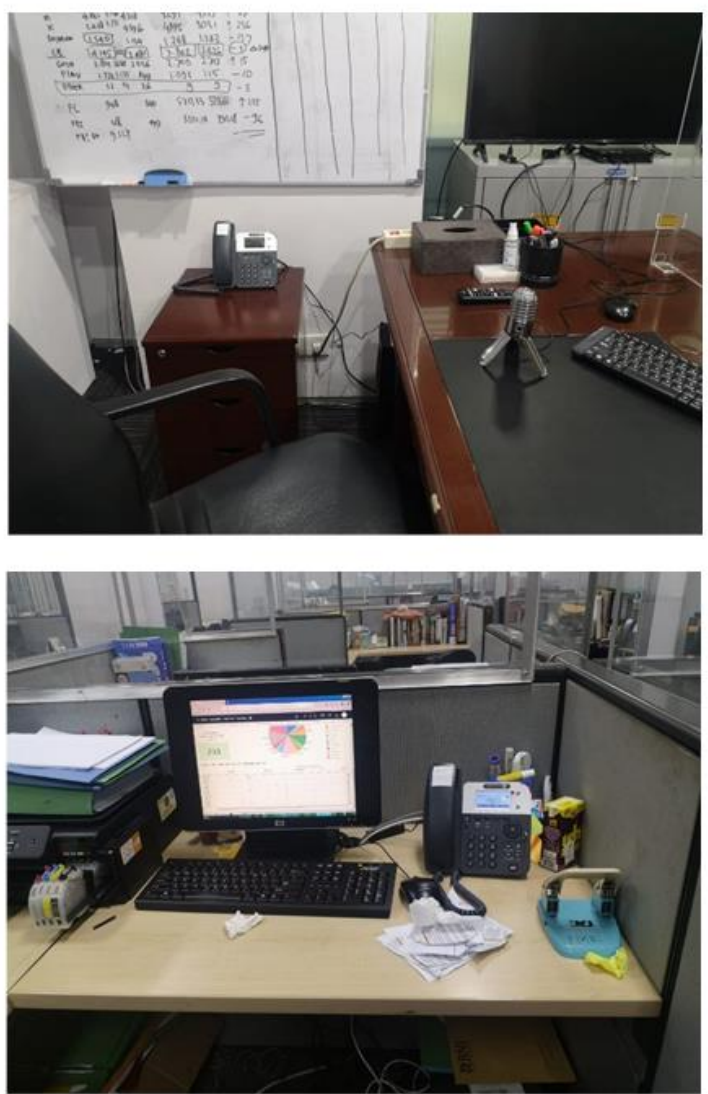

Gambar Telephone di Meja Staff
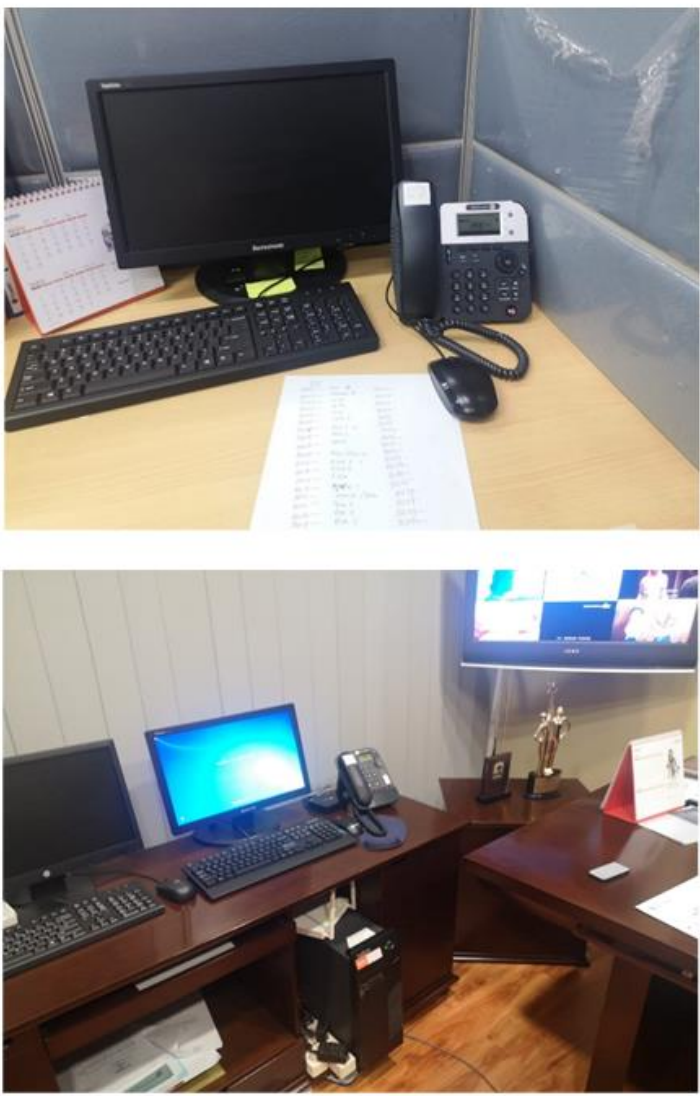

Gambar 3. Perangkat IP Phone disisi Pengguna

Perangkat IP Phone yang digunakan tipe 8001/8001G DeskPhone produk Alcatel Luncent. Setelah dilakukan uji fungsi dengan tahapan sebagai berikut :

1. Uji panggilan telepon antar ruangan dan dari operator,

2. Uji panggilan konfren antar ruangan dan dari operator,

3. Uji panggilan keluar dari pengguna langsung atau lewat operator,

4. Uji panggilan masuk lewat operator atau langsung ke nomor pengguna dan menggunakan fitur konfren.

5. Uji greeting atau mesin penjawab otomatis dari server perekam percakapan telepon.

6. Uji server voip untuk melayani perobahan nomor user dan penambahan user baru.

7. Uji jaringan LAN yang digunakan untuk ip phone, apakah tidak mengganggu aplikasi yang digunakan serta koneksi ke jaringan internet baik lokal maupun vpn BNI.

Setelah semua hasil pengujian dilakukan bersama pengguna layanan dan dinyatakan tidak ada kendala, maka Berita Acara uji Terima Lapangan Refreshment PBX Outlet di Site Kantor BNI Kanwil Padang dinyatakan selesai dan ditandatangani oleh pihak BNI Padang.

\section{SIMPULAN}

Pengujian sistem merupakan pengujian program perangkat lunak yang lengkap dan terintegrasi. Perangkat lunak atau yang lebih sering dikenal dengan sebutan software hanyalah satuan elemen dari sistem berbasis komputer yang lebih besar. Biasanya, perangkat lunak dihubungkan dengan perangkat lunak dan perangkat keras lainnya.

Black Box Testing atau yang lebih sering dikenal dengan sebutan pengujian fungsional merupakan metode pengujian perangkat lunak yang digunakan untuk menguji perangkat lunak tanpa mengetahui struktur internal kode atau program. Dalam pengujian ini, tester menyadari apa yang harus dilakukan oleh program tetapi tidak memiliki pengetahuan tentang bagaimana melakukannya.

Pada Black Box Testing ini dilakukan pengujian yang didasarkan pada detail aplikasi seperti tampilan aplikasi, fungsi-fungsi yang ada pada aplikasi, dan kesesuaian alur fungsi dengan bisnis proses yang diinginkan oleh customer. Black-box testing ini lebih menguji ke tampilan luar (Interface) dari suatu aplikasi agar mudah digunakan oleh pengguna. Pengujian ini tidak melihat dan menguji source code program. Black-box testing bekerja dengan mengabaikan struktur kontrol sehingga perhatiannya hanya terfokus pada informasi domain.

Tes "Kotak Hitam atau Black Box" hanya terdiri dari meninjau fungsi-fungsi dari aplikasi, yaitu jika melakukan 
apa yang seharusnya, tidak peduli bagaimana melakukannya. Struktur dan fungsi internalnya tidak dipelajari. Dengan demikian penguji perlu mengetahui apa peran sistem itu, dan fungsinya, tetapi tidak tahu mekanisme internalnya. Dia memiliki profil "pengguna".

Jadi metode ini bertujuan untuk memeriksa, setelah tahap akhir proyek, apakah perangkat lunak atau aplikasi berfungsi dengan baik, dan melayani penggunanya secara efisien. Biasanya, penguji mencari fungsi yang hilang atau salah; antarmuka, kinerja, inisialisasi program dan kesalahan keluar; struktur data atau kesalahan akses basis data eksternal.

Untuk ini, mereka menyiapkan skenario berdasarkan jalur pengguna yang berbeda yang dapat diikuti pada sistem yang akan diuji. Semua fungsi harus diperhitungkan, agar semuanya telah diuji pada akhir operasi. Setiap tes mengikuti skenario, memeriksa untuk setiap fungsi, jika input yang valid diterima, yang tidak valid ditolak, dan tentu saja, setiap waktu, jika output atau hasil yang diharapkan memang diperoleh. Itu adalah metode "coba-coba".

Jadi untuk melakukan Black Box Testing seseorang tidak harus memiliki kemampuan coding atau TDD coding, Tes ini bisa dilakukan oleh pengguna, tim marketing bahkan user sebagai kuisionernya.

\section{DAFTAR PUSTAKA}

Anshori, Isa, "Integrasi Jaringan PABX dengan Jaringan VoIP di ITS", Tugas Akhir Teknik Elektro-ITS, 2008.

Susantok, Mochamad, "Studi Analisis Pengukuran Performansi dan Kualitas Layanan (QoS) pada Jaringan VoIP Berbasis Session Initiation Protocol", Tugas Akhir Teknologi Informasi PENS - ITS, 2007.

Kurniawan, "Pengujian Kualitas Percakapan Dalam Jaringan VoIP Menggunakan NIST Emulator", Tugas Akhir Teknik Elektro - ITB, 2007.

Kristalina, Prima, "Praktikum Instalasi VoIP server (IP segment)", 2009.

Kristalina, Prima, "Praktikum Instalasi VoIP server (Integrasi IP dan Telephony Network)", 2009.

Kristalina, Prima, "trafik Telekomunikasi 1 \& 2", 2009

Pengertian PABX, http://www.total.or.id

http://www.cisco.com/warp/public/788/pkt-voice-general/bwidth_consume.htm

Trabatas Tharom, Teknik dan Bisnis VoIP, Elex Media Komputindo, Jakarta, 2002.

Edhi Wahyu, Trafik Telekomunikasi Bab-1, http://edhywahyu.com

Methods for Subjective Determination of Transmission Quality, ITU - T P.800, 1996.

https://adalah.co.id/white-box-testing/

https://www.dosenpendidikan.co.id/white-box-testing/

https://student-activity.binus.ac.id/himsisfo/2016/10/perbedaan-white-box-testing-dan-black-box-testing/

https://socs.binus.ac.id/2020/07/02/teknik-dalam-white-box-dan-black-box-

testing/\#: :text=White\%20Box\%20Testing\%20adalah\%20salah,ada\%20yang\%20salah\%20atau\%20tidak.

https://www.konsepkoding.com/2020/07/pengertian-perbedaan-black-box-white-grey-box.html

https://medium.com/skyshidigital/pengujian-sistem-52940ee98c77 